\title{
Optimal short-term hydro-thermal scheduling using multi- function global particle swarm optimization
}

\author{
Surender Reddy Salkuti \\ Department of Railroad and Electrical Engineering, Woosong University, Republic of Korea
}

\begin{tabular}{l}
\hline \hline Article Info \\
\hline Article history: \\
Received Feb 6, 2020 \\
Revised Apr 10, 2020 \\
Accepted Apr 24, 2020 \\
\hline
\end{tabular}

\section{Keywords:}

Generation scheduling

Hydro generators

Hydro-thermal scheduling

Meta-heuristic algorithms

Total operating cost

\begin{abstract}
An optimal short-term hydro-thermal scheduling (ST-HTS) problem is solved in this paper using the multi-function global particle swarm optimization (MFGPSO). A multi-reservoir cascaded hydro-electric system with a non-linear relationship between water discharge rate, power generation and net head is considered in this paper. The ST-HTS problem determines the optimal power generation of hydro and thermal generators which is aimed to minimize total fuel cost of thermal power plants during a determined time period. Effects of valve point loading and prohibited operating zones in the fuel cost function of the thermal power plants is examined. Power balance, reservoir volume, water balance and operation constraints of hydro and thermal plants are considered. The effectiveness and feasibility of MF-GPSO algorithm is examined on a standard test system, and the simulation results are compared with other algorithms presented in the literature. The results show that the MF-GPSO algorithm appears to be the best in terms of convergence speed and optimal cost compared with other techniques reported in the literature.
\end{abstract}

Copyright $(2020$ Institute of Advanced Engineering and Science. All rights reserved.

\section{Corresponding Author:}

Surender Reddy Salkuti,

Department of Railroad and Electrical Engineering,

Woosong University,

Jayang-dong, Dong-gu, Daejeon-34606, Republic of Korea.

Email: surender@wsu.ac.kr

\section{NOMENCLATURE}

$a_{i}, b_{i}, c_{i} \quad$ Fuel cost coefficients of $\mathrm{i}^{\text {th }}$ thermal power generating unit.

$\mathrm{t}$ Index for time interval.

$\mathrm{T}$

$\mathrm{M}$

Total number of time intervals for scheduling period.

$\mathrm{N}$

$\varphi_{j}$

$\tau$

$I_{j t}$

$P_{i}^{\min }, P_{i}^{\max }$

$P H_{j}^{\min }, P H_{j}^{\max }$

$V_{j}^{\min }, V_{j}^{\max }$

Total number of thermal plants.

Total number of hydro plants.

Set of upstream units directly above the hydro plant.

Water delay time between reservoir and its upstream.

Natural inflow into reservoir $j$ at time interval t.

Minimum and maximum power generation of thermal power plant $\mathrm{i}$.

Minimum and maximum power generation of hydro plant $\mathrm{j}$.

$q_{j}^{\min }, q_{j}^{\max }$

Minimum and maximum water volume of reservoir $\mathrm{j}$.

Minimum and maximum water discharge of hydro plant $\mathrm{j}$.

\section{INTRODUCTION}

Generally, the hydro power plants are considered as the multi-purpose projects, used to generate the electrical power, and they are responsible for the fulfillment of irrigation requirements of nearby zone. 
The optimal short-term hydro-thermal scheduling (ST-HTS) problem determines the optimal power generation of hydro and thermal generators which aims to minimize total fuel cost of thermal plants during a determined time period. This is a constrained power system optimization problem, which has non-linear, complex characteristics with various types of constraints including power balance, water balance, physical limitations on the reservoir and turbine flow rate, water transport delay between the connected reservoirs, and loading limits of both hydro and thermal power plants. In general, the objective of hydrothermal scheduling (HTS) problem is to minimize the total fuel cost of thermal generating units [1].

A comprehensive review on the application of heuristic methods to obtain optimal generation scheduling of hydro-thermal systems by comparing the implemented procedures from different points of view is presented in $[2,3]$. In the literature, various classical and evolutionary based optimization techniques have been developed for solving the optimal ST-HTS problem. Some of the evolutionary algorithms used for solving the ST-HTS problem include: particle swarm optimization (PSO) [4], fully-informed PSO [5], two-swarm based PSO search strategy [6], couple-based PSO [7], hybrid simulated annealing/genetic algorithm [8], quasi-oppositional teaching learning based optimization [9], improved harmony search algorithm [10], successive approximation approach [11], improved TLBO algorithm [12], accelerated PSO [13], flower pollination algorithm [14], symbiotic organisms search algorithm [15], Grey wolf optimizer [16], recurrent neural network [17], modified flower pollination algorithm [18], etc.

Some of the literature is also available for solving the multi-objective based ST-HTS problem by optimizing cost and emission using normal boundary intersection and VIKOR in [19], lexicographic optimization and normal boundary intersection method in [20], enhanced multi-objective bee colony optimization algorithm in [21]. Multi-objective based approach for a hydro-thermal-wind complementary system of real case in China is proposed in [22]. Recently, a probabilistic ST-HTS problem is solved by considering the wind and solar PV powers and various algorithms reported for solving this problem include: Crow search algorithm (CSA) [23], simultaneous peak regulation strategy [24], GA-based multi-objective optimization model [25], probability interval optimization model [26], etc.

In this paper, multi-function global particle swarm optimization (MF-GPSO) algorithm [27] is used to solve the ST-HTS problem. The proposed MF-GPSO algorithm is applied for solving the daily generation scheduling of a test hydro system with four interconnected cascade hydro plants. Here, the multi-reservoir cascaded hydro-electric system with non-linear relationship between water discharge rate, net head and power generation is considered. Power balance, water balance, reservoir volume and operation constraints of hydro and thermal power plants are considered. Simulation results demonstrate the effectiveness, feasibility and validity of the proposed method in terms of solution precision, when compared with all other algorithms reported in the literature. The MF-GPSO algorithm can easily be extended to any other complex optimization problems faced by the utilities.

The remainder of this paper is organized as follows: Section 2 presents the mathematical formulation for an optimal short-term hydro thermal scheduling (ST-HTS) problem. The description of multi-function global particle swarm optimization (MF-GPSO) algorithm is presented in Section 3. Simulation results and discussion is presented in Section 4. Finally, Section 5 summarizes the contributions with concluding remarks.

\section{ST-HTS: PROBLEM FORMULATION}

The objective of ST-HTS problem is to allocate the water discharge among shorter time intervals to minimize fuel cost of thermal generating units during the scheduling period, while satisfying different equality and inequality constraints $[28,29]$. ST-HTS problem is aimed to minimize the total thermal power generation cost, by using the availability of hydro resources as much as possible. It can be formulated as, minimize, total production cost (TPC), i.e.,

$$
T P C=\sum_{t=1}^{T} \sum_{i=1}^{M}\left[C_{i t}\left(P_{i t}^{T}\right)\right]
$$

where $P_{i t}$ is thermal power generation of $\mathrm{i}^{\text {th }}$ thermal plant during time $\mathrm{t}, C_{i t}\left(P_{i t}\right)$ is the production cost for generating the thermal power $P_{i t}$. In general, $C_{i t}\left(P_{i t}\right)$ is expressed as a quadratic cost function of thermal power generation, and it is given by,

$$
C_{i t}\left(P_{i t}^{T}\right)=a_{i}+b_{i} P_{i t}^{T}+c_{i}\left(P_{i t}^{T}\right)^{2}
$$

The fuel cost function of thermal generating units considering valve point loading (VPL) effect is expressed as,

$$
T P C=\sum_{t=1}^{T}\left[\sum_{i=1}^{M}\left[a_{i}+b_{i} P_{i t}^{T}+c_{i}\left(P_{i t}^{T}\right)^{2}+\left|d_{i} \times \sin \left(e_{i} \times\left(P_{G i}^{\min }-P_{i t}^{T}\right)\right)\right|\right]\right]
$$


A thermal generating unit with prohibited operating zones (POZs) has discontinuous input-output characteristics, and it is difficult to find the actual POZ by performance testing or real operating records. In general, the best economy is achieved by avoiding the operation in areas that are in actual operation. The feasible operating zones of operation of $i^{\text {th }}$ generator can be expressed as,

$$
P_{i t}^{T} \in\left\{\begin{array}{c}
P_{G i}^{\min } \leq P_{i t}^{T} \leq P_{G i, 1}^{l} \\
P_{G i, k-1}^{u} \leq P_{i t}^{T} \leq P_{G i, k}^{l}\left(k=2, \ldots, N_{z i}\right) \\
P_{G i, N_{z i}}^{u} \leq P_{i t}^{T} \leq P_{G i}^{\max }
\end{array}\right.
$$

The above ST-HTS problem is solved subjected to the following equality and inequality constraints.

\subsection{Equality constraints for the ST-HTS problem}

\subsubsection{Power balance constraints}

The total power generation from hydro and thermal units is the sum of total system load plus system losses in each hour of scheduling period.

$$
P_{i t}+\sum_{j=1}^{N} P H_{j t}=P_{D t}+P_{l o s s, t} t=1,2, \ldots, T
$$

where $P_{D t}$ is system load during time period $\mathrm{t}$, and $P_{\text {loss }, t}$ is transmission losses of system during time period $\mathrm{t}$. The hydro power generation $\left(\mathrm{PH}_{j t}\right)$ as a function of water discharge rate and storage volume is expressed as [30],

$$
P H_{j t}=c_{1 j} V_{j t}^{2}+c_{2 j} q_{j t}^{2}+c_{3 j}\left(V_{j t} q_{j t}\right)+c_{4 j} V_{j t}+c_{5 j} q_{j t}+c_{6 j}
$$

Here, $c_{1 j}, c_{2 j}, c_{3 j}, c_{4 j}, c_{5 j}$ and $c_{6 j}$ are power generation coefficients of $\mathrm{j}^{\text {th }}$ hydro power plant.

\subsubsection{Hydraulic continuity constraint}

Storage reservoir volume limits with given initial and final volumes are expressed as,

$$
V_{j t}=V_{j, t-1}+\sum_{m=1}^{\varphi_{j}}\left(q_{m, t-\tau}+S p l_{m, t-\tau}\right)+I_{j t}-q_{j t}-S p l_{j t} m \epsilon \varphi_{j}
$$

where $S p l_{j t}$ is the water spillage of hydro plant $\mathrm{j}$ at time interval $\mathrm{t}$.

\subsection{Inequality Constraints for the ST-HTS Problem}

\subsubsection{Capacity limits of thermal power generating units}

The power generation limits of equivalent thermal generator is expressed as,

$$
P_{i}^{\min } \leq P_{i t} \leq P_{i}^{\max }
$$

\subsubsection{Capacity limits hydro generators}

The operating range of $\mathrm{j}^{\text {th }}$ hydro power generator at $\mathrm{t}^{\text {th }}$ hour is expressed as,

$$
P H_{j}^{\min } \leq P H_{j t} \leq P H_{j}^{\max }
$$

\subsubsection{Constraint on reservoir capacity}

The operating range of reservoir storage volume of $\mathrm{j}^{\text {th }}$ hydro power plant at $\mathrm{t}^{\text {th }}$ hour is limited by,

$$
V_{j}^{\min } \leq V_{j t} \leq V_{j}^{\max }
$$

where $V_{j t}$ is the water volume of reservoir $\mathrm{j}$ at the end of time interval $\mathrm{t}$.

\subsubsection{Constraint on water discharge rate}

The operating range of water discharge rate of $\mathrm{j}^{\text {th }}$ hydro power plant at $\mathrm{t}^{\text {th }}$ hour is limited by [31],

$$
q_{j}^{\min } \leq q_{j t} \leq q_{j}^{\max }
$$

where $q_{j t}$ is the water discharge of hydro plant $\mathrm{j}$ at time interval $\mathrm{t}$. 


\section{MF-GPSO ALGORITHM}

Particle swarm optimization (PSO) is a population based optimization technique for simulating the social behavior similar to the flocking behavior of birds. PSO is initialized with a group of particles called solutions and searches for an optimum through a number of generations. In each generation, each and every particle is updated by the following two best values stored. First one is the best value it has seen so far, this is called $p_{\text {best }}$. Another best value tracked by the particle swarm optimizer is the best value, obtained so far by any particle in the population. This is called as $\mathrm{g}_{\text {best }}$. In the searching process of PSO, if an individual finds a current optimum position (not global optimum position), then all other individuals will move closer to it, and then these individuals are in the dilemma of local optimum position. This situation is known as the premature convergence. The simple approach to overcome this problem is to increase the swarm size [27]. However, it leads to the higher calculation capacity and the execution time. This is the main drawback of classical PSO. There are many improvements are proposed to the classical PSO to overcome the local convergence problem. Since inception of the algorithm several improvements have been proposed in the literature.

Inertia weight parameter $(\omega)$ was introduced in PSO so as to improve the performance of original PSO. $\omega$ plays the role of balancing local and global search capability of PSO. For the better performance, the $\omega$ must be changed non-linearly, dynamically to have better dynamics of balance between the local and global searching capabilities. Fuzzy Adaptive-PSO (FA-PSO) [30] is developed to design a fuzzy system to dynamically adapt $\omega$. In another, variant of PSO, a constriction factor $(\chi)$ is introduced, which increases the algorithm's ability to converge to a good solution. From reference [27], it can be observed that the search capability of PSO becomes saturated when the population density exceeds a certain value. To overcome this, reference [27] has proposed an approach which divides the particles into two parts for different functions, and based on this the multi-function global particle swarm optimization (MF-GPSO) is proposed. In MF-GPSO algorithm, the swarm of particles are divided into two parts i.e., local convergence and global convergence functions. The detailed implementation procedure and pseudo code of MF-GPSO algorithm are presented in [27]. The flow chart of MF-GPSO algorithm is depicted in Figure 1.



Figure 1. Flowchart of multi-function global particle swarm optimization (MF-GPSO) 


\section{SIMULATION RESULTS AND DISCUSSION}

As mentioned earlier, in this paper, the MF-GPSO algorithm is used for solving the ST-HTS problem [31]. The test system that is considered in this paper, a test system is considered same as in reference [32]. It consists of multi-chain, 4 hydro power plants connected in cascade, and an equivalent thermal power plant. The scheduling time period considered is 1 day with hourly intervals. The considered hydraulic system is characterized by river transport delay between successive reservoirs, variable natural inflow rates into each reservoir, variable head hydro plants, POZs of water discharge rates, variable load demand over the scheduling period. The VPL data with POZs of turbines are taken from reference [33]. The fuel cost characteristics of the equivalent thermal power plant with VPL effect is given by,

$$
f\left(P_{i t}\right)=5000+19.2 P_{i t}+0.002\left(P_{i t}\right)^{2}+\left|700 \sin \left[0.085\left(P_{i t}^{\min }-P_{i t}\right)\right]\right|
$$

The minimum and maximum power limits of equivalent thermal generator are $500 \mathrm{MW}$ and $2500 \mathrm{MW}$ respectively, whereas for hydro power plants are $0 \mathrm{MW}$ and $500 \mathrm{MW}$, respectively. Here, 3 different case studies are performed to demonstrate the suitability and effectiveness of MF-GPSO algorithm for solving the optimal ST-HTS problem, and they are,

a) Case Study 1: System without valve point loading (VPL) (quadratic cost curve), and prohibited discharge zones (POZs) effects.

b) Case Study 2: System without VPL effect, and with POZs effect.

c) Case Study 3: System with VPL and POZs effects.

\subsection{Case study 1}

In this case study, the quadratic cost curve of thermal generator is considered without VPL and POZs effects. Figures 2(a) and 2(b) depicts the hourly hydro power plant discharge and reservoir volumes for Case study 1 .

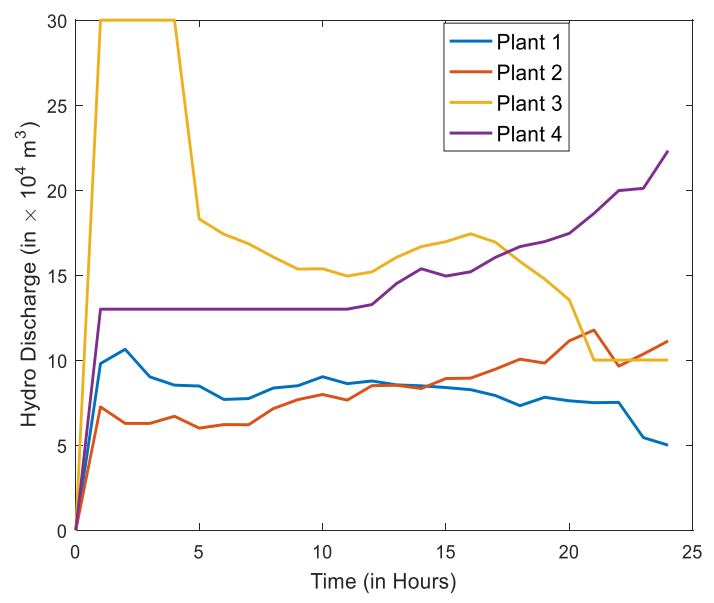

(a)

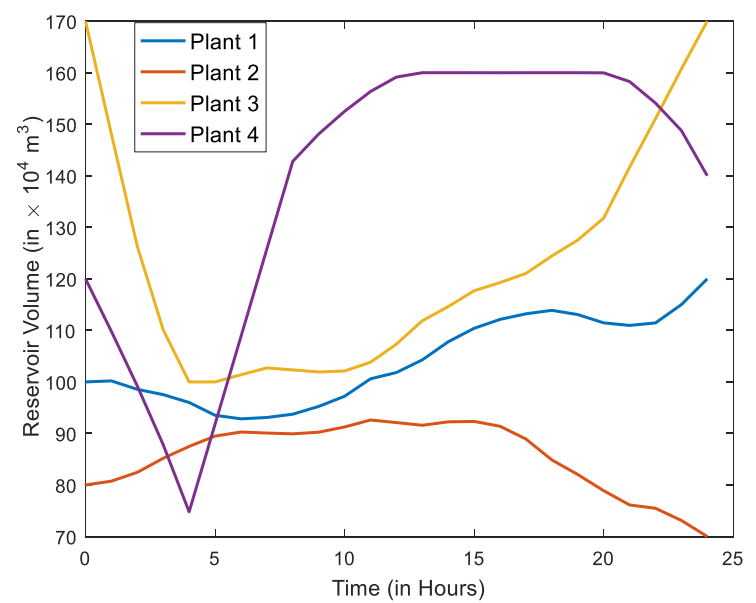

(b)

Figure 2(a), (b). Hourly hydro plant discharge $\left(\times 10^{4} \mathrm{~m}^{3}\right)$ and reservoir storage volumes $\left(\times 10^{4} \mathrm{~m}^{3}\right)$ for Case Study 1

The optimum operating cost obtained after solving the optimal ST-HTS problem using MF-GPSO is 922102.54\$. Table 1 depicts the optimum operating cost obtained with other evolutionary algorithms reported in the literature. The optimum cost obtained from the MF-GPSO algorithm are compared with local vision of PSO with inertia weight (LWPSO), local vision of PSO with constriction factor (LCPSO), improved particle swarm optimization (IPSO), modified seeker optimization algorithm (MSOA), dynamic programming (DP), non-linear programming (NLP), evolutionary programming (IFEP), differential evolution (DE), and clustered adaptive teaching learning based optimization (CATLBO) algorithms are reported in Table 1. The results obtained with MF-GPSO algorithms gives better result compared to DP, NLP, IFEP, DE, IPSO, MSOA, and CATLBO algorithms, while satisfying the reservoir end-volume constraints. 
Table 1. Comparison of optimal costs for test system with quadratic cost function without VPL and POZs effects (Case Study 1)

\begin{tabular}{cccc}
\hline Algorithm & Optimum operating cost $(\$)$ & Algorithm & Optimum operating cost $(\$)$ \\
\hline LWPSO & 925383.8 & GA & 926707.00 \\
LCPSO & 925618.5 & NLP & 924249.48 \\
DE & 923574.31 & FEP & 930267.92 \\
MDE & 922555.44 & CEP & 930166.25 \\
IPSO & 922553.49 & IFEP & 930129.82 \\
MSOA & 922355 & CATLBO & 922266.04 \\
DP & 928919.15 & MF-GPSO & $\mathbf{9 2 2 1 0 2 . 5 4}$ \\
\hline
\end{tabular}

\subsection{Case study 2}

Figures 3(a) and 3(b) depicts the hourly hydro plants discharge and reservoir storage volumes for Case Study 2. The obtained optimum fuel of equivalent thermal generator using MF-GPSO algorithm is 912525.8\$.

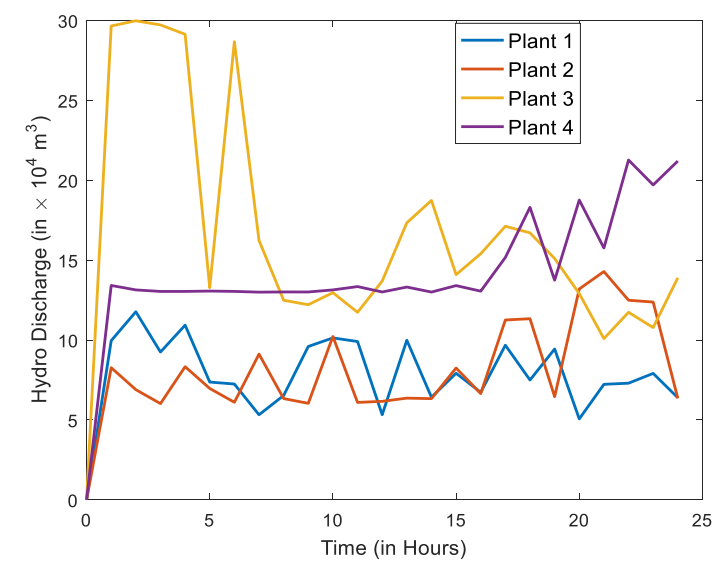

(a)

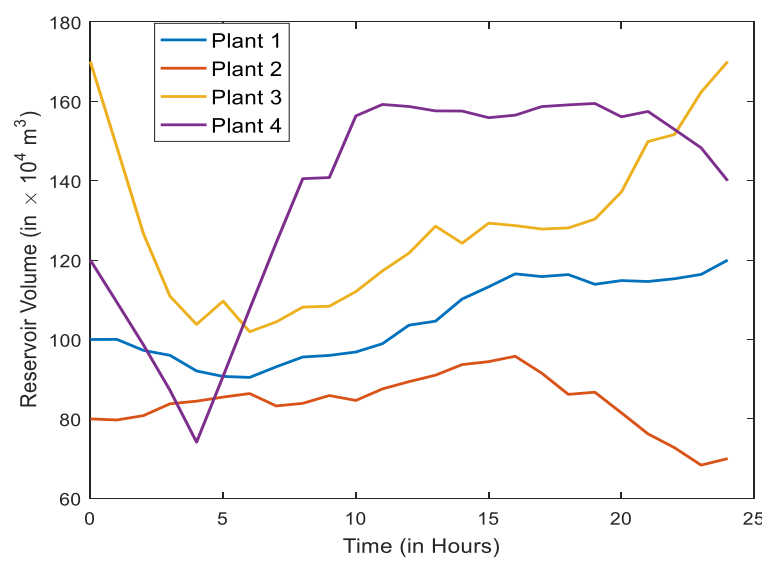

(b)

Figure 3(a), (b). Hydro plant discharge $\left(\times 10^{4} \mathrm{~m}^{3}\right)$ and reservoir storage volumes $\left(\times 10^{4} \mathrm{~m}^{3}\right)$ for Case Study 2

\subsection{Case study 3}

Figures 4(a) and 4(b) depicts the hourly hydro plants discharge and reservoir storage volumes for Case Study 3. The optimum fuel cost obtained in this case using MF-GPSO algorithm is 924315.8\$. The obtained optimum fuel costs of equivalent thermal generators with different algorithms are reported in Table 2. From this table, it can be observed that the total cost obtained with DE algorithm is 928236.94\$, IFEP algorithm is 933949.25\$, IPSO is $925978.84 \$$, MSOA is $925961 \$$, and CATLBO algorithm is $924532.78 \$$.

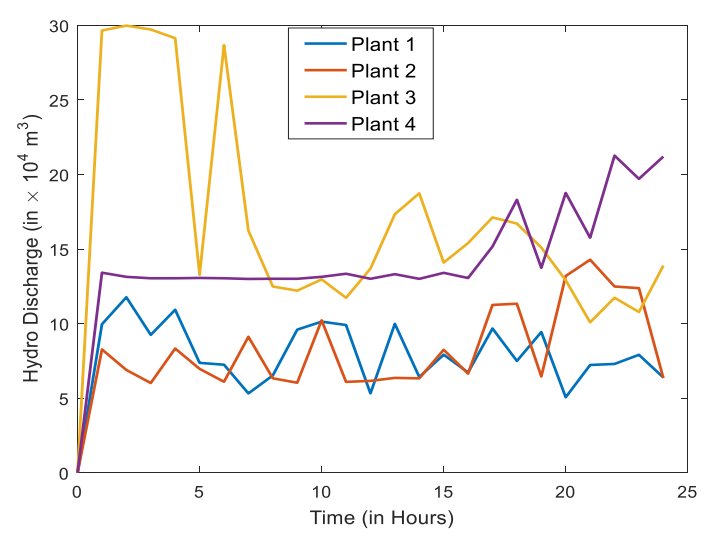

(a)

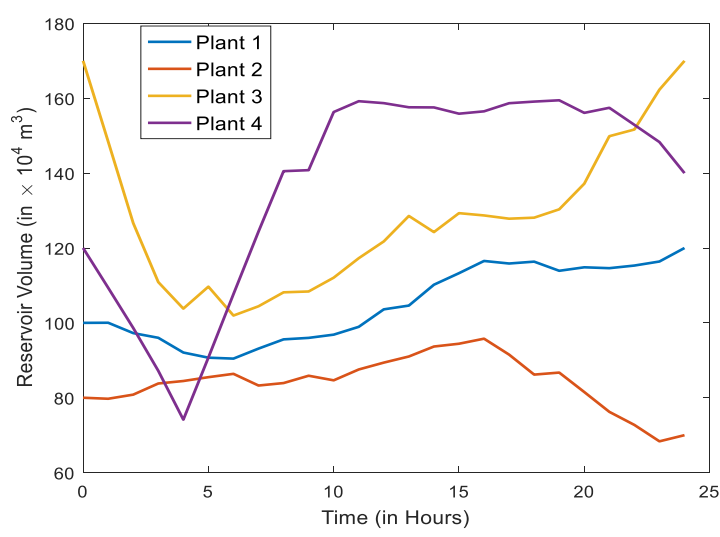

(b)

Figure 4(a), (b). Hourly hydro plant discharge $\left(\times 10^{4} \mathrm{~m}^{3}\right)$ and storage volumes $\left(\left(\times 10^{4} \mathrm{~m}^{3}\right)\right)$ for Case Study 3 
Table 2. Comparison of optimal costs for test system with valve point loading (VPL) and prohibited

\begin{tabular}{cc} 
discharge zones (POZs) effects (Case Study 3) \\
\hline Algorithm & Minimum cost $(\$)$ \\
\hline DP & 935617.76 \\
NLP & 936709.52 \\
IFEP & 933949.25 \\
DE & 928236.94 \\
IPSO & 925978.84 \\
MSOA & 925961 \\
CATLBO & 924532.78 \\
MF-GPSO & 924315.8 \\
\hline
\end{tabular}

As mentioned earlier, the optimum fuel cost obtained with MF-GPSO algorithm is $924315.8 \$$, which is a better solution compared to DP, NL, IFEP, DE, IPSO and CATLBO algorithms. Therefore, the optimum fuel cost obtained with the MF-GPSO algorithm is lesser compared to all other results reported in the literature.

\section{CONCLUSIONS}

A novel optimization approach called multi-function global particle swarm optimization (MF-GPSO) algorithm is applied for solving the optimal short-term hydro-thermal scheduling (ST-HTS) problem. This optimal ST-HTS determines the optimal generation schedules of hydro and thermal generators to optimize the total fuel cost of thermal power plants. Effects of valve point loading and prohibited operating zones in the fuel cost function of the thermal plants is examined in this paper. The suitability and performance of MF-GPSO algorithm on ST-HTS problem is evaluated on a test system. The performance of MF-GPSO algorithm is tested on a standard sample test system considering three different case studies. From the simulation results, it can be observed that the MF-GPSO algorithm applied to ST-HTS problem is excellent in terms of convergence characteristics and optimum operating cost.

\section{ACKNOWLEDGEMENTS}

This research work has been carried out based on the support of "Woosong University's Academic Research Funding - (2019-2020)".

\section{REFERENCES}

[1] A. Esmaeily, F. Raeisi, A. Ahmadi, M.R. Ahmadi, "A note on short-term hydro-thermal scheduling", Energy Conversion and Management, vol. 126, pp. 1178-1186, 2016.

[2] M.N. Heris, B.M. Ivatloo, G.B. Gharehpetian, "Short-term scheduling of hydro-based power plants considering application of heuristic algorithms: A comprehensive review", Renewable and Sustainable Energy Reviews, vol. 74, pp. 116-129, 2017.

[3] A.R. Queiroz, "Stochastic hydro-thermal scheduling optimization: An overview", Renewable and Sustainable Energy Reviews, vol. 62, pp. 382-395, 2016.

[4] S. Banerjee, K. Dasgupta, C.K. Chanda, "Short term hydro-wind-thermal scheduling based on particle swarm optimization technique", International Journal of Electrical Power \& Energy Systems, vol. 81, pp. 275-288, 2016.

[5] M.S. Fakhar, S.A.R. Kashif, M.A. Saqib, T. Hassan, "Non cascaded short-term hydro-thermal scheduling using fully-informed particle swarm optimization", International Journal of Electrical Power \& Energy Systems, vol. 73, pp. 983-990, 2015.

[6] G. Cavazzini, G. Pavesi, G. Ardizzon, "A novel two-swarm based PSO search strategy for optimal short-term hydro-thermal generation scheduling", Energy Conversion and Management, vol. 164, pp. 460-481, 2018.

[7] Y. Wu, Y. Wu, X. Liu, "Couple-based particle swarm optimization for short-term hydrothermal scheduling", Applied Soft Computing, vol. 74, pp. 440-450, 2019.

[8] S.Y.W. Wong, "Hybrid simulated annealing/genetic algorithm approach to short-term hydro-thermal scheduling with multiple thermal plants", International Journal of Electrical Power \& Energy Systems, vol. 23, no. 7, pp. 565-575, 2001.

[9] P.K. Roy, A. Sur, D.K. Pradhan, "Optimal short-term hydro-thermal scheduling using quasi-oppositional teaching learning based optimization", Engineering Applications of Artificial Intelligence, vol. 26, no. 10, pp. 2516-2524, 2013.

[10] M.N. Heris, A.F. Babaei, B.M. Ivatloo, S. Asadi, "Improved harmony search algorithm for the solution of nonlinear non-convex short-term hydrothermal scheduling", Energy, vol. 151, pp. 226-237, 2018.

[11] X. Ge, S. Xia, W.J. Lee, C.Y. Chung, "A successive approximation approach for short-term cascaded hydro scheduling with variable water flow delay", Electric Power Systems Research, vol. 154, pp. 213-222, 2018.

[12] Pasupulati, R.A. Kumar, K. Asokan, "An effective methodology for short-term generation scheduling of hydrothermal power system using improved TLBO algorithm", International Conference on Innovations in Electrical, Electronics, Instrumentation and Media Technology, Coimbatore, 2017, pp. 229-238. 
[13] M.S. Fakhar, S.A. Rehman Kashif, M.A. Saqib, F. Mehmood, H.Z. Hussain, "Non-Cascaded Short-Term PumpedStorage Hydro-Thermal Scheduling Using Accelerated Particle Swarm Optimization", International Conference on Electrical Engineering, Lahore, Pakistan, 2018, pp. 1-5.

[14] T. Balachander, P.A. Jeyanthy, D. Devaraj, "Short term hydro thermal scheduling using flower pollination algorithm", IEEE International Conference on Intelligent Techniques in Control, Optimization and Signal Processing, Srivilliputhur, 2017, pp. 1-5.

[15] H.T. Kahraman, M.K. Dosoglu, U. Guvenc, S. Duman, Y. Sonmez, "Optimal scheduling of short-term hydrothermal generation using symbiotic organisms search algorithm", 4th International Istanbul Smart Grid Congress and Fair, Istanbul, 2016, pp. 1-5.

[16] S. Sutradhar, N.B.D. Choudhury, N. Sinha, "Grey wolf optimizer for Short term Hydrothermal Scheduling problems", Michael Faraday IET International Summit 2015, Kolkata, pp. 522-527.

[17] L. Bao, Y. Shen, P. Miao, W. Li, "Recurrent neural network for solving the short-term hydrothermal scheduling problem", IEEE International Conference on Information and Automation, Lijiang, 2015, pp. 2388-2393.

[18] S. Sutradhar, N.B.D. Choudhury, N. Sinha, "Hydrothermal scheduling using Modified Flower Pollination Algorithm: A parallel approach", IEEE Region 10 Conference, Singapore, 2016, pp. 1696-1700.

[19] M. Simab, M.S. Javadi, A.E. Nezhad, "Multi-objective programming of pumped-hydro-thermal scheduling problem using normal boundary intersection and VIKOR", Energy, vol. 143, pp. 854-866, 2018.

[20] Ahmadi, M.S. Masouleh, M. Janghorbani, N.Y.G. Manjili, A.M. Sharaf, A.E. Nezhad, "Short term multi-objective hydrothermal scheduling", Electric Power Systems Research, vol. 121, pp. 357-367, 2015.

[21] J. Zhou, P. Lu, Y. Li, C. Wang, L. Yuan, L. Mo, "Short-term hydro-thermal-wind complementary scheduling considering uncertainty of wind power using an enhanced multi-objective bee colony optimization algorithm", Energy Conversion and Management, vol. 123, pp. 116-129, 2016.

[22] J. Xu, F. Wang, C. Lv, H. Xie, "Carbon emission reduction and reliable power supply equilibrium based daily scheduling towards hydro-thermal-wind generation system: A perspective from China", Energy Conversion and Management, vol. 164, pp. 1-14, 2018.

[23] S. Das, A. Bhattacharya, A.K. Chakraborty, "Fixed head short-term hydrothermal scheduling in presence of solar and wind power", Energy Strategy Reviews, vol. 22, pp. 47-60, 2018.

[24] X. Wang, J. Chang, X. Meng, Y. Wang, "Short-term hydro-thermal-wind-photovoltaic complementary operation of interconnected power systems", Applied Energy, vol. 229, pp. 945-962, 2018.

[25] L. Liu, Q. Sun, Y. Wang, Y. Liu, R. Wennersten, "Research on Short-term Optimization for Integrated Hydro-PV Power System Based on Genetic Algorithm", Energy Procedia, vol. 152, pp. 1097-1102, 2018.

[26] J.J. Chen, Y.B. Zhuang, Y.Z. Li, P. Wang, Y.L. Zhao, C.S. Zhang, "Risk-aware short term hydro-wind-thermal scheduling using a probability interval optimization model", Applied Energy, vol. 189, pp. 534-554, 2017.

[27] Z.H. Ruan, Y. Yuan, Q.X. Chen, C.X. Zhang, Y. Shuai, H.P. Tan, "A new multi-function global particle swarm optimization", Applied Soft Computing, vol. 49, pp. 279-291, 2016.

[28] B. Yu, X. Yuan, J. Wang, "Short-term hydro-thermal scheduling using particle swarm optimization method", Energy Conversion and Management, vol. 48, no. 7, pp. 1902-1908, 2007.

[29] S. Das, A. Bhattacharya, A.K. Chakraborty, "Solution of Short-Term Hydrothermal Scheduling Problem Using Quasi-Reflected Symbiotic Organisms Search Algorithm Considering Multi-fuel Cost Characteristics of Thermal Generator", Arabian Journal for Science and Engineering, vol. 43, no. 6, pp. 2931-2960, 2018.

[30] S.R. Salkuti, "Short-term optimal hydro-thermal scheduling using clustered adaptive teaching learning based optimization", International Journal of Electrical and Computer Engineering, vol. 9, no. 5, pp. 3359-3365, 2019.

[31] M. Shaaban, H. Zeynal, K. Nor, "MILP-based short-term thermal unit commitment and hydrothermal scheduling including cascaded reservoirs and fuel constraints", International Journal of Electrical and Computer Engineering, vol. 9, no. 4, pp. 2732-2742, 2019.

[32] S.O. Orero, M.R. Irving, "A genetic algorithm modeling framework a solution technique for short term scheduling of hydro-thermal system", IEEE Transactions on Power Systems, vol. 13, pp. 501-518, 1998.

[33] N. Sinha, R. Chakrabarti, P.K. Chattopadhyay, "Fast evolutionary programming techniques for short term hydrothermal scheduling", IEEE Transactions on Power Systems, vol. 18, no. 1, pp. 214-219, 2003. 